\title{
Crashworthiness Simulation of Front Bumper Model of MOROLIPI V2 During Head-on Collision
}

\author{
Aditya Sukma Nugraha, Arif Santoso and Hendri Maja Saputra \\ ${ }^{1}$ Research Centre for Electric Power and Mechatronics-Indonesian Institute of Science
}

\begin{abstract}
It is necessary to conduct an impact test for bumper collision. The use of bumper as a protective components of a vehicle during collision. On this Paper, a crashworthiness simulation of front bumper model with correspond to the size of MOROLIPI V2 is conducted. The purpose of this study was to obtain simulation result used as a reference to predict mechanical behaviour of bumper due to collision. The Simulation result can be predicted deformation after collision, von misses stress criteria after collision with static dummy load. To simulate impact on bumper, ANSYS Explicit Dynamics is used. Simulations were run at three values of mobile robot speeds $(5,10$ and $20 \mathrm{~m} / \mathrm{s}$ ). The simulation results also show contact force due to the collision, deformation, stress and internal energy of the bumper beam. It was known that the speed of the vehicle is the dominant parameter determine the results of the crashworthiness simulation.
\end{abstract}

\section{INTRODUCTION}

With the advance of technology in the world of robotics, the level of movement in robotics are also required to be better. One of these is mobile robot which is a vehicle running using wheel. There are a lot of electronic components and control systems inside which are useful to run mobile robot in accordance with the given command. These components usually have a low collision resistance. One way to protect these components at the time of collision is by using a bumper. The placement of front bumper on the mobile robot MOROLIPI is shown in the schematic drawing in figure 1.

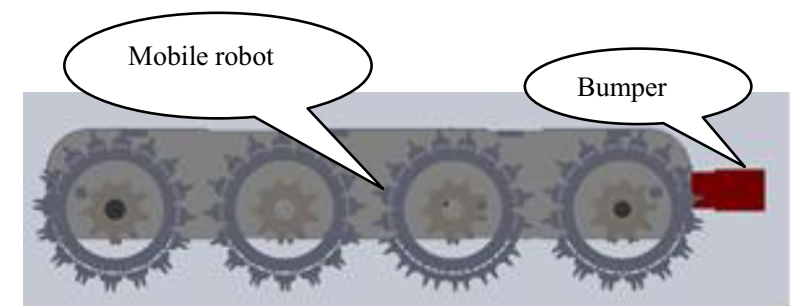

Figure 1. Mobile robot schematic

In this paper, the crashworthiness of front bumper that has a function to protect the component will be analyse. Research on bumper crashworthiness has actually been done both experimentally and by using finite element method [1][2]. Crashworthiness simulation is actually used in the automotive industry to predict how big the effects of a collision on the energy absorption and also deformation caused by the collision [3]. In this paper, the analysis will be carried out by the finite element method simulations using ANSYS Explicit Dynamics so that the impact of the collision can be shown with this software.

\section{BASIC THEORY}

Based on the standard design of the structure of the vehicle with sufficient rigidity and minimum weight that meet crashworthiness criteria, impact load received by the vehicle is an accepted load due to collision. The load is a function of mass and velocity of objects collide. Applying the concept of crashworthiness on the bumper design optimization, the energy generated by the impact is absorbed and converted into displacement (deflection) [1][2].

By using the law of energy balance, it is obtained that the total energy produced is the sum of kinetic energy and internal energy. Total initial energy is defined as the kinetic energy of the colliding object, ie then the energy equation can be written with the following equation:

$$
\frac{1}{2} m_{1} v_{1}^{2}+\frac{1}{2} m_{2} v_{2}^{2}=\left(\frac{1}{2} m_{1}\left(v_{1}^{\prime}\right)^{2}+U_{1}\right)+\left(\frac{1}{2} m_{2}\left(v_{2}^{\prime}\right)^{2}+U_{2}\right)
$$

With $\mathrm{v} 2=0$, then : 


$$
\frac{1}{2} m_{1} v_{1}^{2}=\left(\frac{1}{2} m_{1}\left(v_{1}^{r}\right)^{2}+U_{1}\right)+\left(\frac{1}{2} m_{2}\left(v_{2}^{r}\right)^{2}+U_{2}\right)
$$

Where m: mass; v: Velocity; U: strain energy; W: work Strain Energy (U) is defined equal to the work (W) where:

$$
\begin{aligned}
& U=W=\int_{0}^{x} F(x) d x \\
& F=k x \\
& W=\frac{1}{2} k x^{2} \\
& W=U=\frac{1}{2} F x \\
& U=\frac{1}{2} \frac{F^{2}}{k}
\end{aligned}
$$

The energy absorbed by the object, using the equation above can be represented by a force - displacement curve.

\section{FINITE ELEMENT MODELLING}

Finite element modelling is necessary to simplify the calculation process. Basically the concept is done by dividing the structural elements to be analysed into finite numbers of elements. Finite element modelling method used in this paper is one of the numerical methods to solve many cases in engineering world. One of them is to solve the problem of structural and dynamical analysis.

To facilitate the process of analysis, the completion of the finite element method was performed using ANSYS Explicit Dynamics software. Front bumper model was built using Solidworks. The result was then applied to 3D modelling using ANSYS to show the collision phenomenon occurs with variations in vehicle speed. Simulation steps carried out in crashworthiness modelling were in accordance with steps that are commonly used in the completion of finite element $[3][4][5][6][7]$. In a study conducted by E. Isaksson and M. Oldenburg [8][9], a modelling has been done by reducing vehicle mass into several centralized lumped mass as shown below.

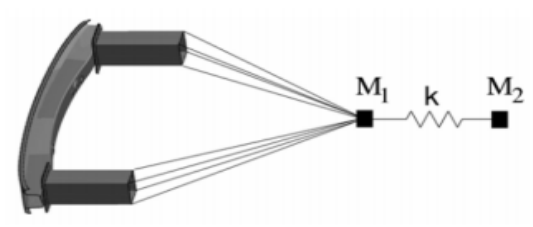

Figure 2 Finite Element Model which simplifies the shape of the vehicle in a lumped mass

\section{DATA AND DESIGN BUMPER MODEL}

While internal component in mobile robot safety may be defined and evaluated in various ways, one of them is maximizing energy absorption of bumper during impact has been adopted for vehicle designs [7]. And then in this paper Computer Aided Engineering (CAE) to create 3D model used in Solidworks imported from CAD files that are corresponded to the actual shape of the vehicle. The length of the bumper is: $290 \mathrm{~mm}$, width: $65 \mathrm{~mm}$, height: $50 \mathrm{~mm}$, with a thickness: $3 \mathrm{~mm}$. Material from the bumper is designed to use low-carbon steel. Figure 3 shows a bumper model along the wall as a static dummy load.

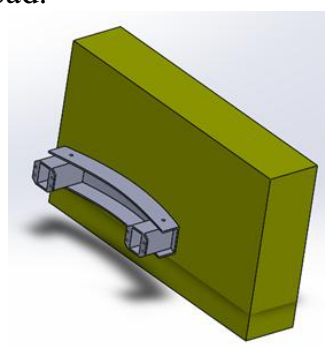

(a)

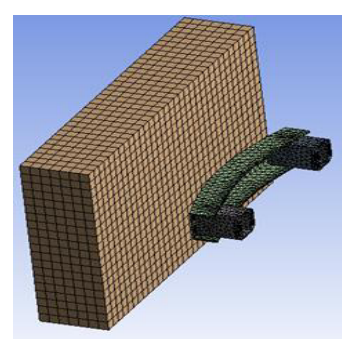

(b)
Figure 3. (a) Model Bumper along the wall as a static dummy load, (b) Meshing Model

Material on the bumper assumed to be aluminum, a soft metal which is expected to absorb a lot of energy. Concrete walls are used as static dummy Load, i.e. as the material hit by the bumper in the Crashworthiness simulation. The specifications of the materials used in the simulation are as follows [10][11]:

Tabel 1 Mechanical Properties of Materials

\begin{tabular}{|c|l|c|c|c|}
\hline No & \multicolumn{1}{|c|}{ Items } & Aluminium & $\begin{array}{c}\text { Concrete } \\
\text { Wall }\end{array}$ & Units \\
\hline $\mathbf{1}$ & Densitas & 2770 & 2200 & $\mathrm{Kg} \cdot \mathrm{m}^{-3}$ \\
\hline $\mathbf{2}$ & $\begin{array}{l}\text { Modulus } \\
\text { Elastisitas }\end{array}$ & 70 & 21 & $\mathrm{GPa}$ \\
\hline $\mathbf{3}$ & Poisson Ratio & 0,33 & 0,17 & - \\
\hline
\end{tabular}

\section{RESULT AND ANALYSIS}

Crashworthiness simulation was performed using ANSYS Explicit Dynamics software. The simulation results of three cases of speed $(5,10$ dan $20 \mathrm{~m} / \mathrm{s})$ can be seen in the following this figure:

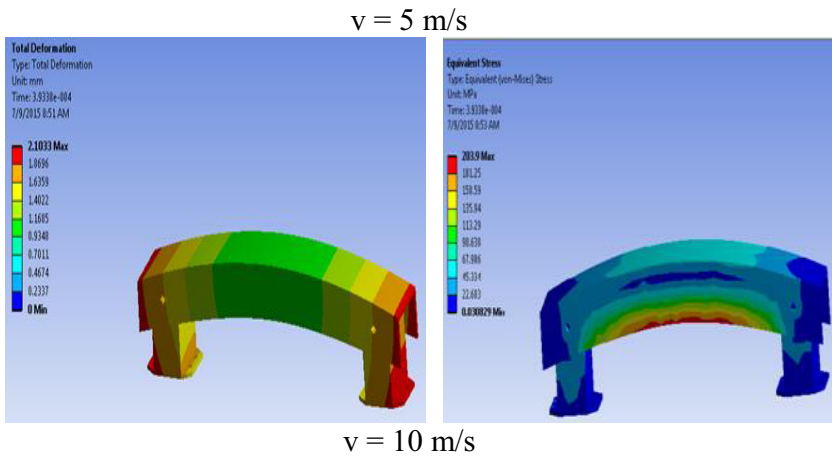



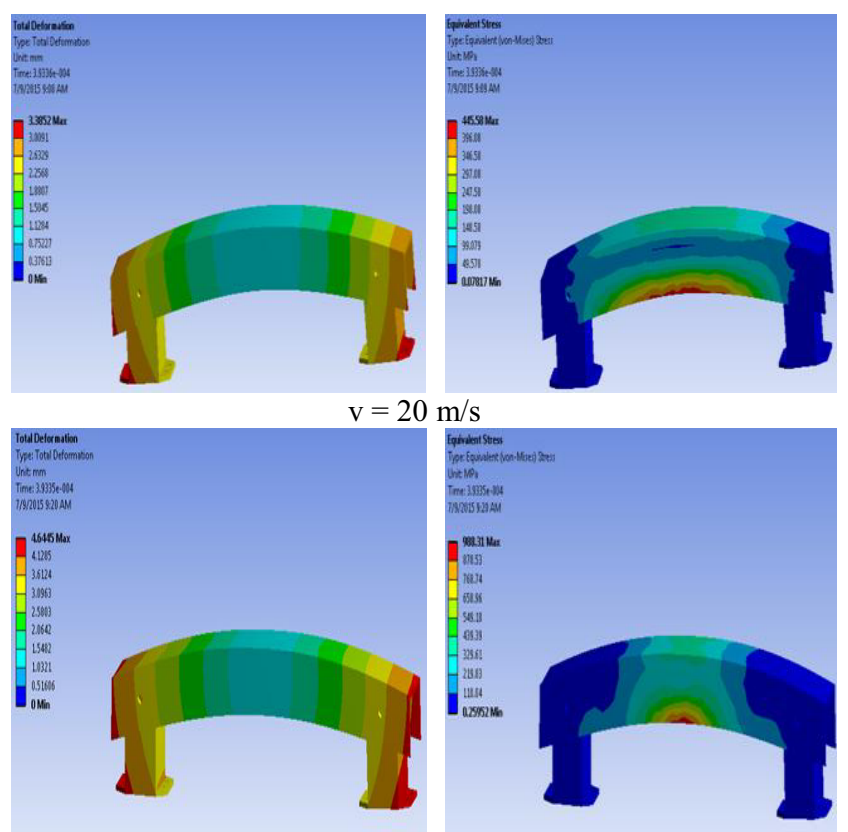

Figure 4 Deformation and stress due to collisions in three variations of speed

In the event of a collision, the bumper components will result of deform as shown in Figure 4, and at times occur which cause deformation of the bumper also produce changes in energy in the energy absorption of the collisions, and finally also result of the contact force between the concrete wall as a static dummy and bumper with variation speed. The results of the contact force and energy absorption during a collision process can be seen in Figure 5 until figure 7.

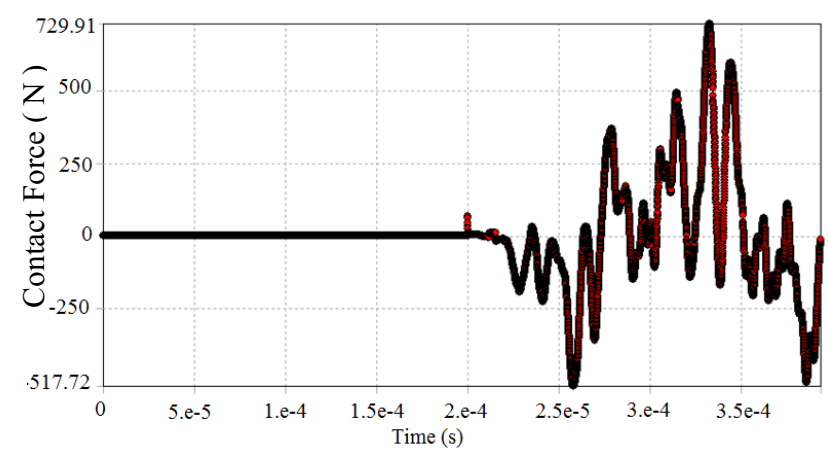

(a)

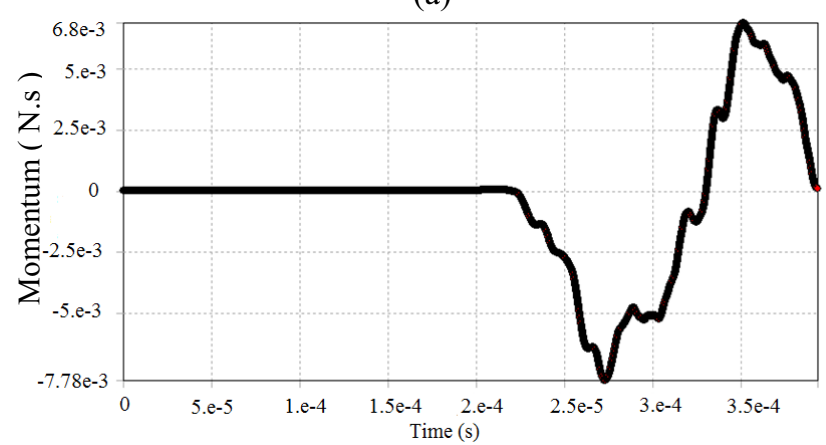

(b)

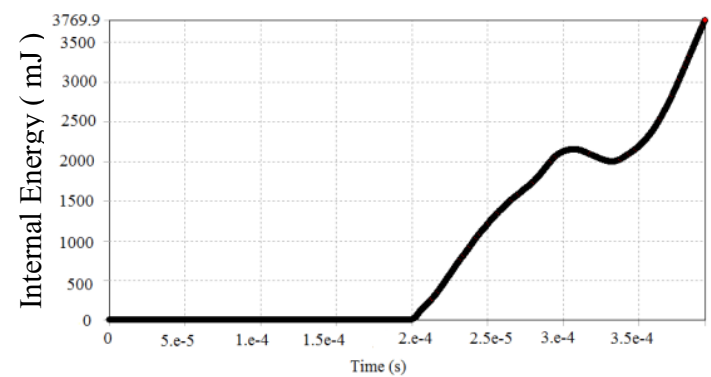

(c)

Figure 5. Graph the results of a collision at a speed of $5 \mathrm{~m} / \mathrm{s}$ (a)contac force,(b)momentum,(c)Internal energy

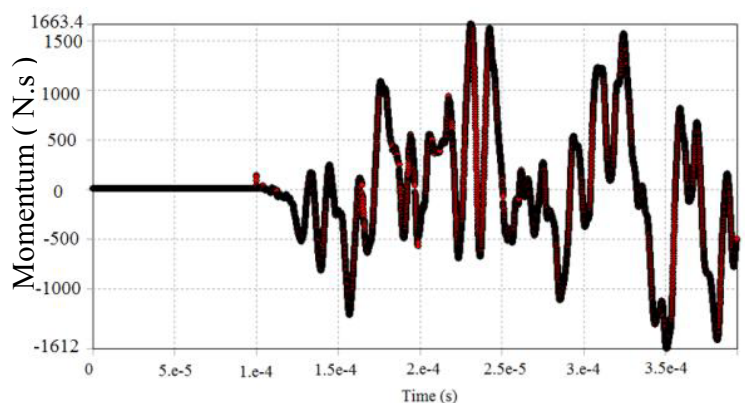

(a)

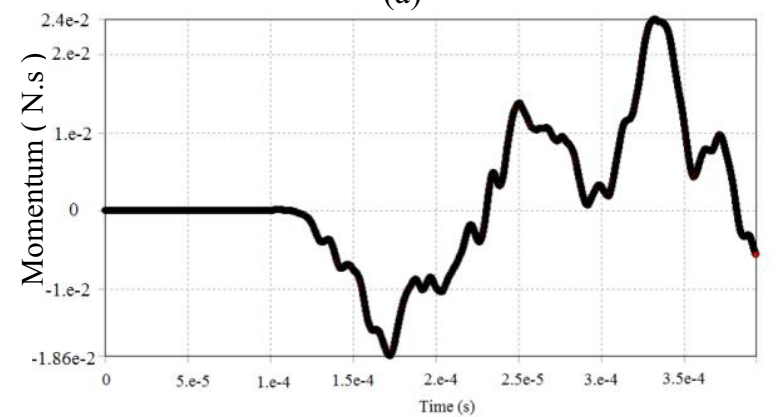

(b)

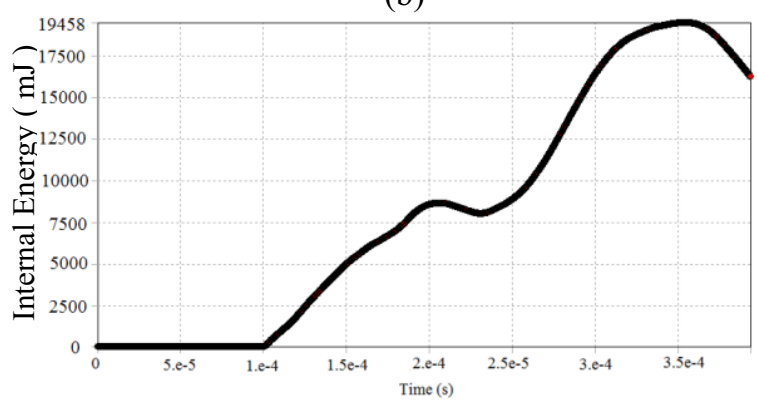

(c)

Figure 6. Graph the results of a collision at a speed of $10 \mathrm{~m} / \mathrm{s}$ (a)contac force,(b)momentum,(c)Internal energy

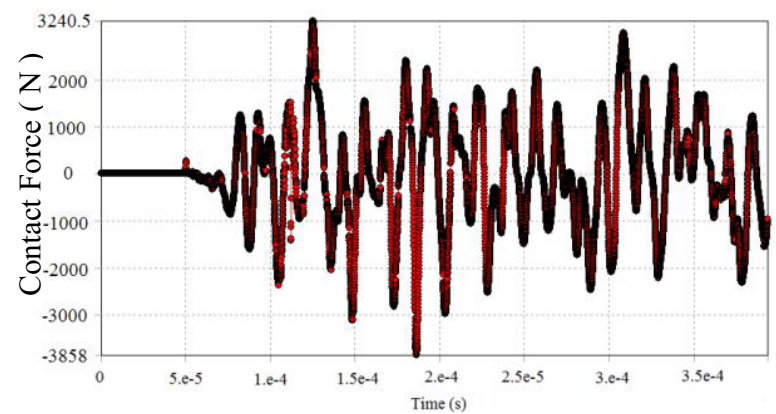

(a) 


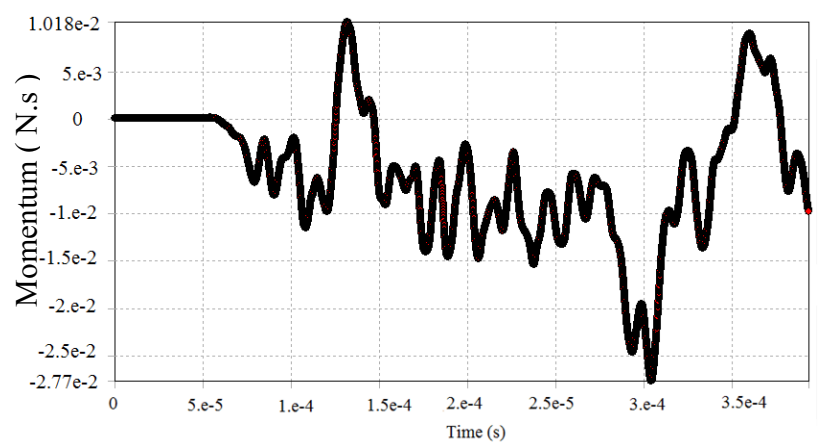

(b)

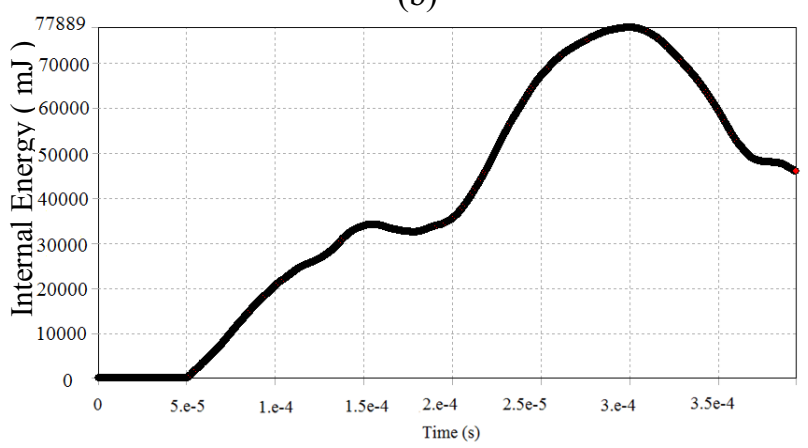

(c)

Figure 7. Graph the results of a collision at a speed of $20 \mathrm{~m} / \mathrm{s}$ (a)contact force,(b)momentum,(c)Internal energy

As seen in the simulation results in Figures $5-7$ it can be seen that the faster bumper crashed into a concrete wall, then the result will be even greater deformation ie from $2.1 \mathrm{~mm}$ at the time of a speed of $5 \mathrm{~m} / \mathrm{s}, 3.35 \mathrm{~mm}$ at the time of speed $10 \mathrm{~m} / \mathrm{s}$ and $4.46 \mathrm{~mm}$ at the current speed of $20 \mathrm{~m} / \mathrm{s}$. Which draws on the results of the figure of simulation is effect of variations in vehicle speed make difference of the internal energy. The bumper result of the absorb energy an increase in very large value that is approximately $400 \%$ from the previous speed.

\section{CONCLUSSION}

From the simulation results it can be said that the difference in speed is the dominant factor that determine the outcome of the collision on the bumper. On further research is needed to validate the experimental test this FEM modeling of this so it can be used as a basis for optimization in the form of bumper when the kinematics associated with the deformation criteria, the contact force and energy absorption due to collisions.

\section{ACKNOWLEDGMENT}

The author would like to thank to Research Centre for Electrical Power and Mechatronics- Indonesian Institute of Science, for facilitating the Finite Element Analysis Simulation using ANSYS.

\section{References}

1. Ma. Q.H, Zhang. C.Y,Han. S.Y,Qin. Z.T. , 2013., "Research on the Crash Safety of The Bumper Base on the Different Standard", International Journal of Security and Its Applications Vol.7, No.6, pp.147-154.

2. Kirkpatrick. S.W, Schroeder. M,Simons. J.W, 2001 , "Evaluation of Passenger Rail Vehicle Crashworthiness", International Journal of Crashworthiness, Vol. 6, No. 1, pp. 95-106.

3. Dyah.K.D, 2014, Analisis Performa Bodi Kendaraan Khusus Tipe Pendobrak( Battering Ram Vehicle)", Tesis, Bandung : Fakultas Teknik Mesin dan Dirgantara, Institut Teknologi Bandung.

4. Logan, Daryl L. (2002) A First Course in the Finite Elemen Method. United States : University of Wisconsin.

5. Teng. T.L.,Chang. K.C. , Nguyen. T.H, 2008., "Crashworthiness Evaluation of Side Door Beam of Vehicle", Technische Mechanic, Brand 28 , 268-278.

6. Farzam Ashkani, Majid Shahravi and Mohsen Amrai, 2014, Effects of contact angle and velocity on crashworthiness characteristics of high-speed train nose, Technical Journal of Engineering and Applied Sciences 4 (3):pp. 85-90

7. Isaksson, Erik., 2006Simulation Methods for Bumper System Development, Erik. Sweden : Lulea University of Technology, 2006. pp.1402-1757

8. Horstemeyer. M.F,Ren. X.C, Fang.H , Acar. E, Wang. P.T,2009, "A Comparative study of design optomisation methodologies for side impact crashworthiness, using injury based versusu energy based criterion", International Journal of Crashworthiness Vol. 14, No. 2, pp. 125-138.

9. Javad Marzbanrad and Mostafa Pahlavani, A System Identification Algorithm for Vehicle Lumped Parameter Model in Crash Analysis,2011, International Journal of Modeling and Optimization, Vol. 1, No. 2, pp.163-168

10. Dewi, R.R.., 2011, Studi Perilaku Model Panel Dinding Bata Pengisi Pada Struktur Beton Bertulang. Surabaya : Teknik Sipil FTSP-ITS.

11. Seyed Yaser Mousavi Siamakani, Abdul Kadir Bin Marsono, Neelam Memon, Shariwati Binti Mansor, Hares Nikookar, Performance of Concrete Walls with Waste and Recycling Materials for Industrial Building Systems, International Journal of Innovative Technology and Exploring Engineering, Volume 4 Issue-2, pp.93-97 